\title{
Caravaca de la Cruz y el Camino de Levante (Murcia): impactos sociales y económicos del primer itinerario espiritual y cultural del sudeste (SE) español, en fase de consolidación
}

\author{
Francisco José Morales Yago*
}

Universidad Nacional de Educación a Distancia (UNED), Departamento de Geografía, Calle Senda del Rey 7, Edificio de Humanidades, 28040 Madrid, España

Recibido: 23 de febrero de 2021 / Aceptado: 27 de mayo de 2021

\begin{abstract}
Resumen
El siglo XIII se considera la fecha inicial del surgimiento de Caravaca de la Cruz (Murcia) como lugar de peregrinaciones. Tras su nombramiento in perpetuum como ciudad jubilar en el año 1998, este enclave ha incrementado de forma exponencial el número de peregrinos y turistas, convirtiéndose en el primer itinerario espiritual y cultural del SE español. Las diversas iniciativas en la potenciación turística han fijado un proceso de valorización continuado con importantes fases de estancamiento en los años no jubilares. Por todo ello, se precisa una mayor consolidación y fijación de este producto turístico. Los indicadores y datos utilizados señalan, a través de la herramienta DAFO, una serie de acciones en áreas de mejora imprescindibles para la potenciación turística, que ayudarían a mejorar el desarrollo local, el nivel de bienestar, el aumento del empleo o la recuperación patrimonial en una ciudad y en una comarca que se encuentran por debajo de los indicadores socioeconómicos a nivel regional y estatal, pero con enormes potencialidades como espacio atractivo para el turismo religioso, cultural y de naturaleza.
\end{abstract}

Palabras clave

Peregrinaciones; turismo; economía; Caravaca de la Cruz; desarrollo local.

\section{Caravaca de la Cruz and the Levante Way (Murcia): Social and economic impacts on the first spiritual and cultural itinerary in south eastern Spain}

\begin{abstract}
The thirteenth century is considered the instigation of the emergence of Caravaca de la Cruz (Murcia) as a place of pilgrimages. After its appointment "in perpetuum" as a jubilee city in 1998, this enclave has exponentially increased the number of pilgrims and tourists, becoming the first spiritual and cultural itinerary of the Spanish SE. The various initiatives in the promotion of tourism have established a process of continued valorization with important phases of stagnation in the non-jubilee years. Therefore, a greater consolidation and fixation of this tourist product is required. The indicators and data used indicate through the SWOT tool a series of actions in areas of essential improvement for the promotion of tourism that would help to improve local development, level of well-being, increase in employment or recovery of heritage in a city and region that is It is below the socioeconomic indicators at the regional and state level but with enormous potential as an attractive space for religious, cultural and nature tourism.
\end{abstract}

\section{Keywords}

Pilgrimages; tourism; economy; Caravaca de la Cruz; local development.

JEL Codes: L83, R58, Q01, Z12.

\footnotetext{
${ }^{*}$ Correspondencia autor: fimorales@geo.uned.es
} 


\section{Introducción}

Las peregrinaciones siempre han estado unidas a la evolución del ser humano sobre el planeta. Las grandes religiones han construido santuarios o espacios sagrados a donde las personas se han desplazado desde sus lugares de origen con la finalidad de buscar un encuentro con lo sagrado o con lo sobrenatural.

La geografía de los lugares de peregrinación es amplia, y supone importantes espacios de concentración de personas. En la mayoría de los casos, aparecen una serie de caminos, de vías o de misiones (Steil y Marques, 2008) que conducen a esos lugares, algunas de ellas con recorridos de varios miles de kilómetros. En la Tabla 1 indicamos algunos de los más destacados.

Tabla 1. Principales lugares sagrados del planeta a donde llegan peregrinaciones

\begin{tabular}{lll}
\hline $\begin{array}{l}\text { Lugar } \\
\text { La Meca } \\
\text { (Arabía Saudí) }\end{array}$ & Religión & Características \\
$\begin{array}{l}\text { Bodh Gaya } \\
\text { (India) }\end{array}$ & Budismo & $\begin{array}{l}\text { Cada año recibe a más de 13 millones de peregrinos de todo el mundo, que } \\
\text { llevan visitándola } 1.400 \text { años, desde el siglo VII. }\end{array}$ \\
$\begin{array}{l}\text { Varanasi o Benarés } \\
\text { (India) }\end{array}$ & Hinduísmo & $\begin{array}{l}\text { Ciudad Patrimonio de la Humanidad desde 2002. Recoge un importante } \\
\text { complejo de templos, entre los que destaca el de Mahabodhi. }\end{array}$ \\
$\begin{array}{l}\text { Ise } \\
\text { (Japón) }\end{array}$ & $\begin{array}{l}\text { Situada en la orilla oeste del río Ganges, es uno de los siete lugares sagrados } \\
\text { para la religión hindú. Con 20 millones de peregrinos al año, es el centro de } \\
\text { peregrinaciones más concurrido del mundo. }\end{array}$ \\
$\begin{array}{l}\text { Roma } \\
\text { (Italia) }\end{array}$ & $\begin{array}{l}\text { Es la ciudad sagrada de la religión sintoísta. Alberga dos santuarios. } \\
\text { Cristianismo }\end{array}$ & $\begin{array}{l}\text { Es la sede del Papa. Se visitan, entre otros lugares, El Vaticano, donde, } \\
\text { según la tradición, se encuentran los restos de San Pedro y de San Pablo } \\
\text { Extramuros. }\end{array}$ \\
$\begin{array}{l}\text { Jerusalén } \\
\text { (Israel) }\end{array}$ & $\begin{array}{l}\text { Judaísmo, } \\
\text { cristianismo e el Muro de las Lamentaciones los judíos rezan y evocan la venida de } \\
\text { Islam }\end{array}$ & $\begin{array}{l}\text { Cristo, y también es el lugar donde surgió el cristianismo a través del miste- } \\
\text { rio de Jesús de Nazaret. Para los musulmanes, es la ciudad sagrada donde el } \\
\text { profeta Mahoma subió al cielo. Es Patrimonio de la Humanidad desde 1981. }\end{array}$ \\
$\begin{array}{l}\text { Santiago de Compostela } \\
\text { (España) }\end{array}$ & $\begin{array}{l}\text { Surgió como ciudad de peregrinaciones en el siglo IX. Según la tradición, } \\
\text { acoge los restos del apóstol Santiago. Es Patrimonio de la Humanidad desde } \\
\text { 1985. }\end{array}$ \\
\hline
\end{tabular}

Fuente: elaboración propia a partir de: https://vivecamino.com/las-rutas-de-peregrinacion-mas-importantes-del-mundono-302/\#grandes-peregrinaciones-religiosas-en-el-mundo

Dentro de la tradición cristiana, la dilatada historia de esta religión ha ido generando a través del tiempo un importante número de lugares sagrados como catedrales, santuarios, ermitas e iglesias singulares como, entre otros, los santuarios de Lourdes (Francia), Fátima (Portugal), Guadalupe (México), Divina Misericordia (Polonia), Medjugorje (Bosnia y Herzegovina) o Nuestra Señora de la Aparecida (Brasil). España es uno de los países de la cristiandad que más lugares de peregrinaciones y romerías reúne. De las cinco ciudades santas reconocidas por la Iglesia con peregrinaciones a perpetuidad, tres de ellas se encuentran en España -Santiago de Compostela, Santo Toribio de Liébana y Caravaca de la Cruz- junto a Roma (Italia) y Jerusalén (Israel).

El culto a la Santa Vera Cruz en Caravaca representa una dilatada presencia en el tiempo, teniendo constancia de su existencia a partir de la segunda mitad del siglo XIII (Torres Fontes, 1969). Estas fechas coinciden con la expulsión musulmana y con la desaparición de la Taifa de Murcia en 1243 por las capitulaciones de Alcaraz con el infante Alfonso de Castilla, en representación de Fernando III, por las que se aceptaba el protectorado de los reinos de Castilla y de León y pasaba a ser territorio de la Encomienda de Santiago, lo que llevó a la instalación de diversas órdenes religiosas (Sánchez Romero, 2009): la Compañía de Jesús en 1570, los Franciscanos en 1571, las Carmelitas Descalzas en 1576, San 
Jerónimo en 1582, los Carmelitas Descalzos en 1587 y los Franciscanos de Santa Clara en 1609. Caravaca de la Cruz se ha consolidado como destino de fe y devoción a la Santa Vera Cruz de forma significativa tras la concesión de un jubileo a perpetuidad y cada siete años desde 1998 por el Papa San Juan Pablo II.

Caravaca de la Cruz es un municipio de la Región de Murcia (Figuras 1 y 2). Se considera por su importancia histórica, por su mayor número de habitantes y por su oferta de servicios como capital y centro administrativo de la comarca del Noroeste. Tiene una población en el año 2020 de 25.688 habitantes, y su término municipal alcanza una extensión de $859,51 \mathrm{~km}^{2}$, lo que significa una densidad de población de 29,88 habitantes $/ \mathrm{km}^{2}$, dato bastante inferior a la media regional (130 hab. $/ \mathrm{km}^{2}$ ) o nacional (92 hab. $\left./ \mathrm{km}^{2}\right)$.

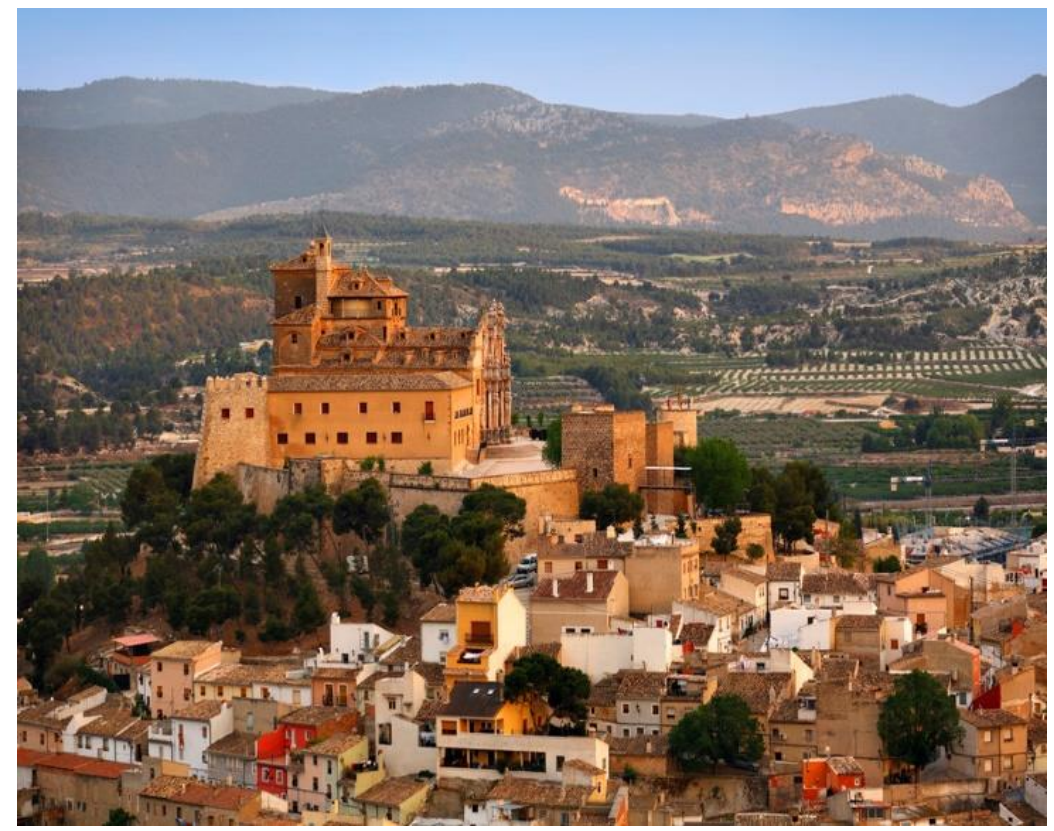

Figura 1. Vista general de Caravaca (2020).

Fuente: https://www.sitiosdeespana.es/articulo/caravaca-de-la-cruz-murcia

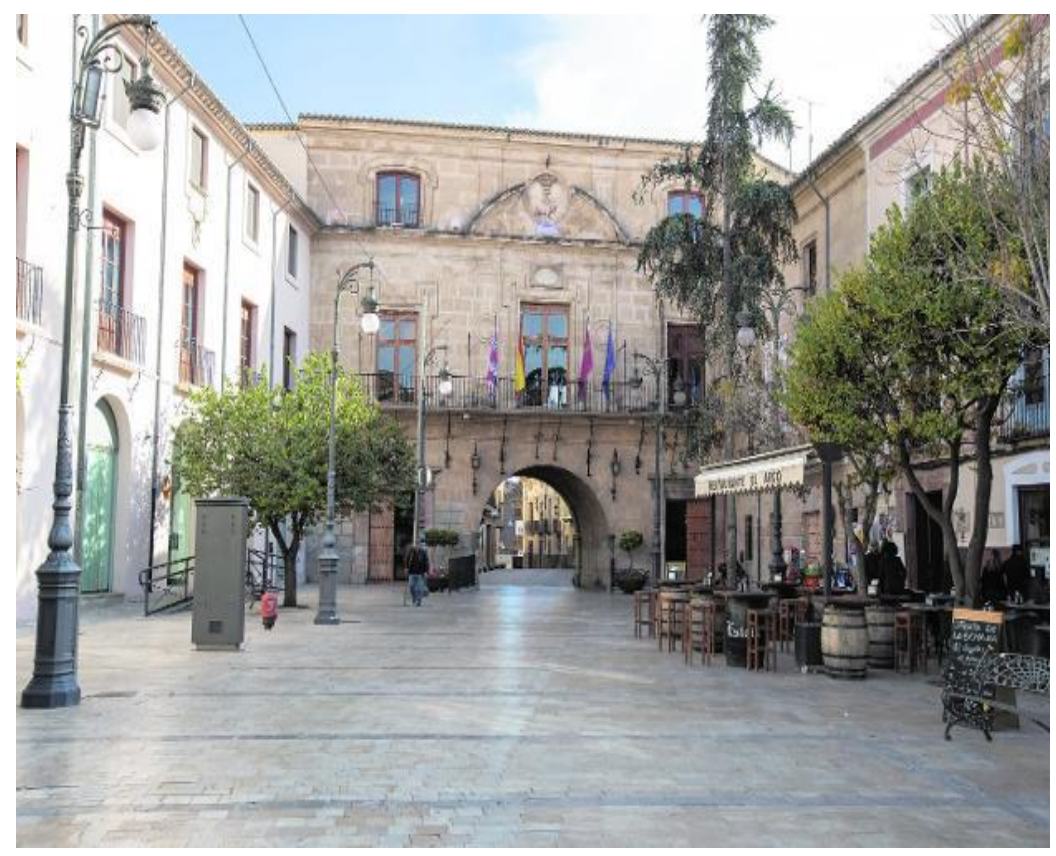

Figura 2. Plaza del Ayuntamiento (2020). Fuente: www.laverdad.es 
Entre los 45 municipios que componen la Región de Murcia, el de Caravaca se sitúa en términos absolutos de población en el número 14, ocupando el número 39 en cuanto a densidad de población. Por su extensión, es uno de los mayores de Murcia, en el quinto lugar, y ocupa el número 20 en todo el conjunto nacional. Está situado a 625 metros sobre el nivel del mar, su altitud media hacia el este es de 600 metros, mientras que hacia el oeste se superan rápidamente los 800 metros. Presenta una localización geográfica clave como cruce de caminos entre Levante y Andalucía, tratándose de un espacio de transición en épocas pasadas entre el Reino Nazarí de Granada y Murcia, donde el núcleo de Caravaca representaba una fortaleza defensiva privilegiada (Molina Molina, 2002) junto a Lorca (García Marín, 2016) (Figura 3).

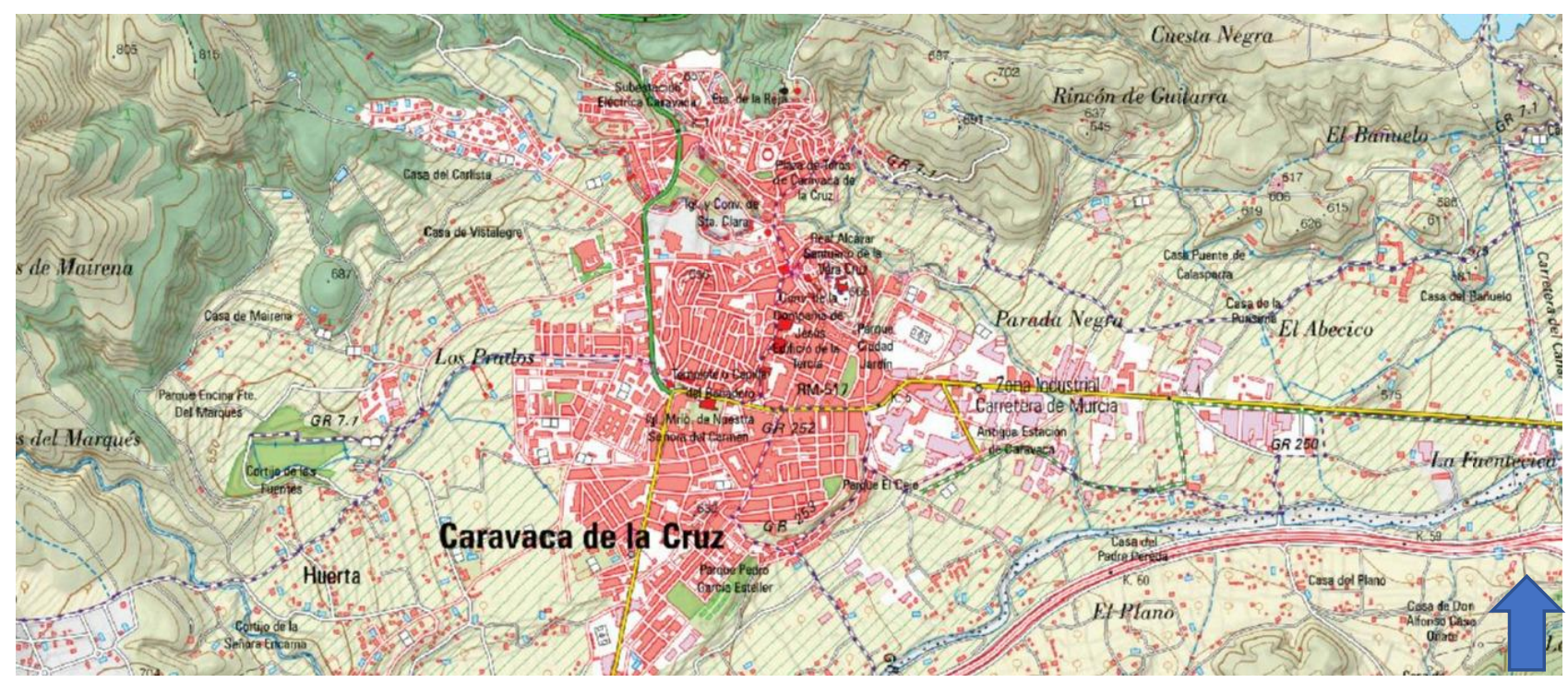

Figura 3. Emplazamiento de Caravaca de la Cruz y morfología del trazado urbano. Escala: 1: 25.000. Fuente: Iberpix (2019) https://www.ign.es/iberpix2/visor/

Dentro de la configuración del término municipal, destaca la existencia de una serie de pedanías, en total 12, que acogen el 19,13\% de la población, mientras que en el núcleo principal vive el 81,87\%, con una población inmigrante del 7,72\% del total, datos mucho más bajos que la media regional (14,1\%) 0 nacional (10,7\%) (Tabla 2).

Tabla 2. Distribución de la población en Caravaca por pedanías y número de extranjeros (2020)

\begin{tabular}{lccc}
\hline & Total & Española & Extranjera \\
\hline Caravaca de la Cruz -municipio- & 25.688 & 23.704 & 1.984 \\
Almudema (La) & 215 & 209 & 6 \\
Archivel & 1.149 & 1.037 & 112 \\
Barranda & 806 & 725 & 81 \\
Benablón & 149 & 128 & 21 \\
Caneja & 141 & 118 & 23 \\
Caravaca de la Cruz -núcleo- & 21.031 & 19.436 & 1.595 \\
Encarnación (La) & 291 & 278 & 13 \\
Huerta & 813 & 744 & 69 \\
Moral (El) & 60 & 43 & 17 \\
Moralejo (El) y Junquera (La) & 66 & 62 & 4 \\
Navares & 353 & 321 & 32 \\
Royos (Los) & 50 & 46 & 4 \\
Singla & 319 & 314 & 5 \\
\hline
\end{tabular}

Fuente: https://econet.carm.es/inicio//crem/sicrem/PU CaravacaDeLaCruzCifras/P8016/sec8.html 
En relación con los datos físicos, la temperatura media anual es de $15,4{ }^{\circ} \mathrm{C}$. Su temperatura media es de $7{ }^{\circ} \mathrm{C}$ en el mes más frío (enero) y de $25^{\circ} \mathrm{C}$ en los meses más calurosos (julio y agosto). En cuanto a las temperaturas extremas, en invierno se pueden alcanzar los $-7^{\circ} \mathrm{C}$, siendo frecuentes las heladas, mientras que en verano se pueden tener temperaturas extremas próximas a los $40{ }^{\circ} \mathrm{C}$. Las precipitaciones presentan unos valores medios alrededor de los $380 \mathrm{~mm} / \mathrm{año}$, siendo la primavera y el otoño las épocas más lluviosas; las lluvias en el verano son muy escasas, y cuando se producen es en forma de tormentas cortas y a veces intensas.

\section{Material y método}

La investigación empleada tiene un carácter mixto, y utilizamos fuentes documentales provenientes de varios organismos oficiales como el Instituto Nacional de Estadística (INE); la Comunidad Autónoma de Murcia, a través del Instituto de Turismo; y los ayuntamientos. A estas fuentes se ha sumado un trabajo realizado a través de entrevistas a expertos y a personas conocedoras de esta temática, y también se ha desarrollado un importante trabajo de campo, visitando la mayor parte de los núcleos de población que componen el espacio de estudio.

Destacamos la importante información documental proporcionada por la Oficina de Turismo del Ayuntamiento de Caravaca de la Cruz y por la Cofradía de la Vera Cruz. La implicación de ambas instituciones ha sido decisiva para profundizar en aspectos estadísticos como la obtención de datos básicos relacionados con la evolución del número de visitas a la ciudad o de los datos relativos a la población como el comportamiento demográfico, las dinámicas de crecimiento o las tasas de actividad económica y de empleabilidad.

Los instrumentos imprescindibles en la búsqueda de información han sido la utilización del catastro urbano y diversos datos proporcionados a través del INE y del Anuario Estadístico de la Región de Murcia, elaborado por la Consejería de Economía, Hacienda y Administración Digital de dicha Comunidad Autónoma. También se ha tenido en cuenta, por un lado, el Plan general de ordenación urbana municipal actual, de 2008, que fijó las directrices de urbanización del espacio geográfico de la ciudad y de su entorno municipal; y, por otro, la Ley 3/1992, de 30 de julio, de patrimonio de la Comunidad Autónoma de la Región de Murcia, que nos ha permitido conocer el marco jurídico que ha ordenado el tratamiento patrimonial de Caravaca, así como la gestión y ordenación de los recursos existentes o la puesta en valor de estos de una forma sostenible y conciliadora (Cebrián Abellán, 2004; Zárate Martín, 2009).

Para la elaboración cartográfica se ha consultado la aplicación Cartomur, diseñada por la Consejería de Urbanismo y Obras Públicas de la Región de Murcia, aunque, finalmente, se ha incorporado cartografía elaborada por otras fuentes que se citan al pie de cada imagen. Por último, se incorporan fotografías extraídas de las fuentes citadas, que ayudan a valorar la imagen del paisaje, y que constituyen un testimonio gráfico que muestra los grandes cambios generados ante las políticas de rehabilitación y renovación de la ciudad, mostrándose también otras imágenes donde aparecen recursos turísticos de gran valor, como las fiestas patronales o las relacionadas con las peregrinaciones al Santuario-Fortaleza de la Vera Cruz, dentro de una dinámica territorial global (Andrés Sarasa, 2002; Espejo Marín, 2008).

Para la realización del estudio se ha aplicado una metodología cualitativa con un nivel de análisis exploratorio cuya herramienta de recogida de datos ha sido la entrevista en profundidad, estandarizada y abierta, es decir, una entrevista configurada por preguntas abiertas, redactadas del mismo modo para todos los entrevistados, y de respuesta libre. El objetivo perseguido con la utilización de este instrumento ha sido la obtención de un gran volumen de información acerca de los impactos que ocasiona el turismo en la ciudad de Caravaca de la Cruz y los itinerarios generados de acceso a la ciudad, la mayoría localizados en la Región de Murcia y en las provincias de Alicante y Albacete, así como el denominado Camino de la Cruz, un proyecto todavía por desarrollar entre Roncesvalles y Caravaca.

La muestra se ha realizado a través de un procedimiento de muestreo no probabilístico por selección experta de agentes implicados, utilizando como criterio de selección la especialidad de los participantes, provenientes en su mayoría del ámbito empresarial, académico y de la investigación. A la hora de seleccionar a los participantes, se ha optado por unos criterios mínimos de homogeneidad- 
-heterogeneidad para mantener la simetría de la relación de los componentes de los grupos, y así asegurar la diferencia de criterios.

Para la recogida de información se ha acudido a personas de fácil acceso de los centros en los que se han aplicado los cuestionarios. Se considera que las personas seleccionadas cuentan con la suficiente formación y experiencia, utilizándose, por tanto, un criterio de selección de expertos, esto es, de personas que conocieran bien el espacio y la temática estudiada. A lo largo de las entrevistas, se han creado momentos de gran interacción entre el entrevistador y los entrevistados; a través de un cuestionario semiestructurado, pero abierto a matizaciones, se ha recogido la información de forma transversal, es decir, recogida de una sola vez con el objetivo de estudiar fenómenos presentes en el momento de realización de la encuesta, lo que ha permitido un estudio tanto descriptivo como analítico, obteniendo estimaciones generales de las variables, comparaciones entre subgrupos (miembros de las asociaciones que promueven la cultura local, autoridades locales, técnicos de turismo, personal de hostelería y restauración, etcétera) y relaciones entre variables. Se ha asignado un código a cada una de las personas entrevistadas, de tal forma que resultase fácil identificar las opiniones de cada una de ellas (Tabla 3).

Tabla 3. Muestra seleccionada en las entrevistas

\begin{tabular}{lcc}
\hline Colectivo & No entrevistas & Código \\
\hline Técnicos de turismo municipales & 3 & TE1-TE3 \\
Responsables de la Fundación Cajamurcia & 1 & CAJ-1 \\
Responsables del Consorcio Vías Verdes & 1 & CVV1-CVV2 \\
Instituto de Turismo de la Región de Murcia & 2 & ITM1-ITM2 \\
Miembros de la Asociación Caravaca Jubilar & 2 & ASC1-ASC3 \\
Miembros de agencias de viajes & 1 & AV1-AV2 \\
Gremio de artesanos & 2 & AR1-AR2 \\
Miembros de sindicatos actividad turística & 1 & SI1-SI2 \\
Miembros de patronales de hostelería & 2 & PH1-PH2 \\
Responsables de la Administración (municipios NO) & 2 & AD1-AD2 \\
\hline
\end{tabular}

Fuente: elaboración propia.

Con respecto a la muestra de informantes, su larga experiencia, su amplia y dilatada trayectoria profesional y la variedad de responsabilidades les hace conocedores del sistema de organización del entorno turístico de la comarca. Estas características, junto con su variedad en las edades y en las funciones desempeñadas, aseguran una información amplia y diversa que, por proceder de fuentes variadas y complementarias, enriquecen la visión por nosotros pretendida. En general, los colectivos participantes se han mostrado receptivos con el tema y muy conscientes de los cambios que se están produciendo en la sociedad y en la economía de la zona en el tiempo presente (Chaves y Faber, 2019).

El análisis DAFO es una herramienta eficaz para el análisis de estudio de la situación de una empresa o de un proyecto, que estudia sus características internas (debilidades y fortalezas) y su situación externa (amenazas y oportunidades) en una matriz cuadrada. Proviene de las siglas en inglés SWOT (Strengths, Weaknesses, Opportunities, Threats), y es una herramienta que permite conocer la situación real en la que se encuentra una organización, una empresa o un proyecto, y planear una estrategia de futuro. También favorece la participación de distintos grupos de interés, ya que los participantes en las entrevistas son expertos o conocedores de la investigación llevada a cabo, lo que indica suficientes garantías de fiabilidad en las respuestas, y ello se incrementa cuando las respuestas llegan a un índice de saturación alto (por encima del 90\% de coincidencias). De la combinación de fortalezas con oportunidades surgen las potencialidades, las cuales señalan las líneas de acción más prometedoras para la organización. Las limitaciones, determinadas por una combinación de debilidades y amenazas, suponen una seria advertencia (Tabla 4), e invitan a la puesta en marcha de acciones que mejoren las perspectivas en la gestión turística (Velasco González, 2009) y una adecuada planificación territorial como destino turístico (Vera Rebollo, López Palomeque, Marchena Gómez y Antón Clavé, 2011). 
Tabla 4. Tabla-matriz análisis DAFO

\begin{tabular}{lll} 
& Oportunidades & Amenazas \\
\hline Fortalezas & $\begin{array}{l}\text { ¿Qué oportunidades externas pueden ser aprove- } \\
\text { chadas por las fortalezas internas? } \\
\text { Potencialidades. }\end{array}$ & $\begin{array}{l}\text { ¿Qué amenazas externas pueden ser contrarrestadas } \\
\text { por las fortalezas internas? } \\
\text { Limitaciones. }\end{array}$ \\
Debilidades & $\begin{array}{l}\text { ¿Qué oportunidades externas pueden ser aprove- } \\
\text { chadas si se superan las debilidades internas? } \\
\text { Desafíos. }\end{array}$ & $\begin{array}{l}\text { ¿Qué amenazas externas no pueden ser contrarresta- } \\
\text { das si no se superan las debilidades internas? } \\
\text { Riesgos. }\end{array}$ \\
\hline
\end{tabular}

Fuente: Cànoves, Villarino, Blanco-Romero, de Uña Álvarez, y Espejo (2014).

Los riesgos (combinación de fortalezas y amenazas) y los desafíos (combinación de debilidades y oportunidades), determinados por su correspondiente combinación de factores, exigirán una cuidadosa consideración a la hora de marcar el rumbo que la organización deberá asumir hacia el futuro deseable. Una vez finalizados los análisis parciales (definidos los objetivos sobre los que se desarrolla el estudio y realizado el trabajo de campo para conocer la realidad sobre la que vamos a hacer dicho estudio), estos nos permitirán realizar un diagnóstico de las debilidades, de las amenazas, de las fortalezas y de las oportunidades para, a continuación, y en función de este análisis, establecer unos objetivos, proponer diferentes estrategias de desarrollo capaces de superar los condicionantes identificados y alcanzar los objetivos de conocimiento del modelo de desarrollo turístico de las tierras del interior, en este caso del término municipal de Caravaca de la Cruz.

El análisis interno examina en profundidad cada uno de los componentes que configuran las características internas de la puesta en valor de las instalaciones y de los recursos turísticos con el propósito de identificar puntos fuertes y débiles en la organización de ellas, la realización de nuevos proyectos o el rendimiento en cuanto a visitas existentes. El análisis externo, por su parte, estudia la situación y las perspectivas del entorno en general para identificar y evaluar las variables que pueden constituir oportunidades o amenazas para el desarrollo de este modelo turístico. Este debe tener en cuenta la situación socioeconómica de los visitantes (Millán Escriche, 2004); las políticas locales, regionales y nacionales; así como el contexto del mundo global en que se desarrolla la economía turística del siglo XXI. La herramienta DAFO es un instrumento habitual en estos tipos de análisis territoriales del turismo y en la elaboración de planes estratégicos para el desarrollo turístico respondiendo a diversas fases como la organización y preparación del plan, investigación y análisis, formulación de propuestas (objetivos, estrategias, actuaciones, recomendaciones, etcétera), ejecución, seguimiento y control.

En la elaboración previa al análisis DAFO se ha realizado una matriz que presenta puntos clave para abordar el conjunto de los procesos estudiados. Se han propuesto un total de 26 ítems a través de una escala tipo Likert de 1 a 5, así como varias preguntas abiertas que identificaran el sentido de las acciones básicas para aplicar el DAFO, lo que se denominaría CAME (Corregir-Afrontar-Mantener-Explotar), como una herramienta importante que extrae las máximas posibilidades del DAFO (Tabla 5).

El análisis CAME aplicado en este trabajo se presenta como una metodología complementaria al análisis DAFO. A través de él se ofrecerán iniciativas y pautas concretas sobre los aspectos más sobresalientes del diagnóstico DAFO, así como estrategias que permitan el desarrollo del acrónimo CAME (Tabla 6).

Tabla 5. Ítems y preguntas para el desarrollo de entrevistas DAFO-CAME

\begin{tabular}{|c|c|c|c|c|c|}
\hline & $\begin{array}{c}\text { Nada } \\
1\end{array}$ & $\begin{array}{l}\text { Poco } \\
2\end{array}$ & $\begin{array}{c}\text { Normal } \\
3\end{array}$ & $\begin{array}{c}\text { Bastante } \\
4\end{array}$ & $\begin{array}{c}\text { Mucho } \\
5\end{array}$ \\
\hline $\begin{array}{l}\text { 1. Aporta beneficios económicos. } \\
\text { 2. Ha mejorado el empleo gracias a este itinerario. } \\
\text { 3. Existe un aumento demográfico en la zona. } \\
\text { 4. Existe actividad turística todo el año. } \\
\text { 5. Se aprovechan los recursos naturales y el paisaje. }\end{array}$ & & & & & \\
\hline
\end{tabular}


Tabla 5 (continuación). Ítems y preguntas para el desarrollo de entrevistas DAFO-CAME

\begin{tabular}{|c|c|c|c|c|c|}
\hline & $\begin{array}{c}\text { Nada } \\
1\end{array}$ & $\begin{array}{l}\text { Poco } \\
2\end{array}$ & $\begin{array}{c}\text { Normal } \\
3\end{array}$ & $\begin{array}{c}\text { Bastante } \\
\quad 4\end{array}$ & $\begin{array}{c}\text { Mucho } \\
5\end{array}$ \\
\hline \multicolumn{6}{|l|}{$\begin{array}{l}\text { 6. Se aprovechan los recursos culturales. } \\
\text { 7. Se nota el impacto del turismo en la zona. } \\
\text { 8. Han mejorado las infraestructuras de transporte. } \\
\text { 9. Ha crecido la oferta inmobiliaria. } \\
\text { 10. Se percibe apoyo de las instituciones públicas. } \\
\text { 11. Ha mejorado la iniciativa privada. } \\
\text { 12. Existen campañas de promoción turística. } \\
\text { 13. Existe un crecimiento de la oferta cultural y del ocio. } \\
\text { 14. Ha aumentado la cantidad de alojamientos. } \\
\text { 15. Ha mejorado la cantidad de los alojamientos. } \\
\text { 16. Se promociona la oferta gastronómica. } \\
\text { 17. Se promocionan las actividades deportivas. } \\
\text { 18. Se organizan eventos y congresos. } \\
\text { 19. Existe una amplia formación educativa. } \\
\text { 20. Vecinos y asociaciones colaboran en la promoción. } \\
\text { 21. Han mejorado los servicios y los equipamientos. } \\
\text { 22. Existen problemas de seguridad en el Camino. } \\
\text { 23. Funciona la conectividad de internet y de la telefonía. } \\
\text { 24. Se percibe un aumento de peregrinos cada año. } \\
\text { 25. Se considera un itinerario sostenible. } \\
\text { 26. Se percibe un aumento de peregrinos extranjeros. }\end{array}$} \\
\hline \multicolumn{6}{|l|}{$\begin{array}{l}\text { 1. ¿Cuáles son los aspectos más necesitados de una mejora } \\
\text { urgente para la promoción de este itinerario cultural y } \\
\text { religioso? } \\
\text { 2. ¿Cuáles serían las principales dificultades en la promo- } \\
\text { ción? }\end{array}$} \\
\hline $\begin{array}{l}\text { A continuación, le pedimos que lleve a cabo un análisis } \\
\text { DAFO sobre la gestión e imagen que tiene la oferta turística } \\
\text { del Camino de la Vera Cruz de Caravaca. }\end{array}$ & FORTALEZAS & & $\mathrm{AM}$ & UNIDADES & \\
\hline $\begin{array}{l}\text { Realice comentarios que entienda que no se le han formu- } \\
\text { lado para la valoración actual y para la mejora del turismo } \\
\text { en el ámbito de este territorio. }\end{array}$ & & & & & \\
\hline
\end{tabular}

Fuente: elaboración propia.

Tabla 6. Desarrollo de la estrategia CAME

\begin{tabular}{lll}
\hline Palabra clave & Características & Estrategias \\
\hline Corregir debilidades. & $\begin{array}{l}\text { Lanzar iniciativas que pueden hacer desaparecer las debilida- } \\
\text { des detectadas. Ello obedece a una planificación consensuada } \\
\text { de iniciativas reales y de rápida implementación. }\end{array}$ & $\begin{array}{l}\text { Estrategia de reorientación y } \\
\text { supervivencia. }\end{array}$ \\
Afrontar amenazas. & $\begin{array}{l}\text { Evitar que las amenazas se conviertan en debilidades, intervi- } \\
\text { niendo con acciones que puedan perjudicar el deterioro en la } \\
\text { evolución turística por causas variadas, como la competitivi- } \\
\text { dad de otros espacios. }\end{array}$ & $\begin{array}{l}\text { Estrategia de supervivencia y } \\
\text { defensiva. }\end{array}$ \\
Mantener fortalezas. & $\begin{array}{l}\text { Tomar medidas eficaces para no perder fortalezas pues, de } \\
\text { esta manera, se mantiene la necesaria competitividad. Es nece- } \\
\text { sario preservar la solidez de aquellos recursos básicos que son } \\
\text { pilares esenciales. }\end{array}$ & Estrategia ofensiva y defensiva. \\
$\begin{array}{l}\text { Explorar/explotar } \\
\text { oportunidades. }\end{array}$ & $\begin{array}{l}\text { Crear estrategias y planificar acciones para convertir las opor- } \\
\text { tunidades en futuras fortalezas. La capacidad de emprendi- } \\
\text { miento, el refuerzo y las alianzas son los elementos clave. }\end{array}$ & $\begin{array}{l}\text { Estrategia de reorientación y } \\
\text { ofensiva. }\end{array}$ \\
\hline
\end{tabular}

Fuente: elaboración propia a partir de https://www.pdcahome.com/8391/analisis-came/ 


\section{Resultados}

Caravaca de la Cruz, como destino turístico e itinerario cultural, presenta importantes potencialidades que se mostrarán tanto en el análisis DAFO-CAME como en una serie de indicadores significativos sobre el incremento de la actividad económica, el registro de visitantes o la puesta en valor de varias rutas de acceso a Caravaca desde diversos puntos de la Región de Murcia, provincias de Albacete y Alicante así como el proyecto del "Camino de la Cruz", que uniría el Camino de Santiago desde Roncesvalles a Caravaca.

\subsection{Análisis DAFO-CAME}

La obtención de los resultados de este análisis es fruto del estudio en profundidad de las entrevistas realizadas y del trabajo de análisis espacial llevado a cabo por el autor de este trabajo. Del mismo modo, también el acceso a bases de datos regionales y municipales fueron primordiales para extraer información, contrastarla y llegar a conclusiones estimativas reales y veraces. Indicamos a continuación, de forma sintética, los puntos más destacados del estudio efectuado respecto del análisis interno (Tabla 7). En relación con el análisis externo, donde figuran amenazas y oportunidades, podemos ver la Tabla 8.

Tabla 7. Análisis interno DAFO-CAME

\begin{tabular}{l} 
Debilidades \\
\hline 1. Excesiva dependencia de los años jubilares que se repi- \\
ten cada siete años; cuando son años ordinarios las pere- \\
grinaciones son poco significativas. \\
2. No existen hoteles con categoría de tres o de cuatro \\
estrellas.
\end{tabular}

3. Necesidad de mejorar la señalética de los "caminos" que llegan a Caravaca.

4. El grado de pernoctaciones en muy bajo.

5. Inversiones públicas en algunos casos desafortunadas.

6. Falta mucho patrimonio por restaurar y poner en valor.

7. Los horarios de acceso a determinados espacios son escasos.

8. La mayoría de los turistas se concentran en el fin de semana.

9. Escaso éxito de los caminos planeados para llegar a Caravaca: Levante, Apóstol, Altiplano, Guadalentín, Andalucía, Cruz, etcétera.

10. Sector servicios poco desarrollado con respecto al comercio.

11. Escasa oferta formativa en hostelería y servicios turísticos.

12. Economía local poco capitalizada para afrontar inversiones en el medio y en el largo plazo.

13. Falta coordinación entre iniciativa pública y privada.

14. Espacio estancado demográficamente.

15. Oferta limitada como espacio de turismo de interior, rural y de aventura.

16. Poca conectividad en el transporte colectivo.

\section{Fortalezas}

1. Jubileo perpetuo desde 1998, uno de los pocos lugares en el mundo.

2. Reconocimiento como Patrimonio Inmaterial de la Humanidad por la Organización de las Naciones Unidas para la Educación, la Ciencia y la Cultura (UNESCO), Fiesta de los Caballos del Vino en mayo.

3. Gran oferta de museos (siete).

4. Patrimonio monumental variado y de gran belleza.

5. Patrimonio natural de gran valor ambiental.

6. Reconocimiento a nivel nacional de la Fiesta de Las Cuadrillas, en la pedanía de Barranda.

7. Localización geográfica excelente, entre Andalucía y Levante.

8. Proximidad a ciudades como Murcia, Lorca o Cartagena.

9. Excelente conexión por autovía con Murcia.

10. Caravaca de la Cruz y su comarca está llena de recursos turísticos naturales y monumentales, por ejemplo poblaciones como Moratalla, Cehegín o Calasparra.

11. Junto a la ruta del vino de Bullas y la monumentalidad de Mula.

12. Vía Verde y puesta en valor.

13. Apoyo institucional desde el Gobierno autonómico con importantes inversiones (García Pérez, 2003).

14. Sensibilidad desde muchas asociaciones y sectores hacia la promoción de este itinerario.

15. Caravaca es capital comarcal por sus múltiples servicios: hospital, escuela de idiomas, conservatorio, sede de la Universidad Nacional de Educación a Distancia (UNED), ocio nocturno, etcétera.

16. Gastronomía destacada.

17. Artesanía reconocida.

Fuente: elaboración propia. 
Tabla 8. Análisis externo DAFO-CAME

\begin{tabular}{|c|c|}
\hline Amenazas & Oportunidades \\
\hline $\begin{array}{l}\text { 1. Fuerte competencia de otros destinos turísticos dentro y } \\
\text { fuera de la Región de Murcia. }\end{array}$ & $\begin{array}{l}\text { 1. El turismo de interior, cultural, es un producto cada vez más } \\
\text { demandado. }\end{array}$ \\
\hline $\begin{array}{l}\text { 2. Falta de inversiones públicas debido al déficit generali- } \\
\text { zado por los efectos de la COVID-19. }\end{array}$ & $\begin{array}{l}\text { 2. Apertura y conectividad con el Camino de Santiago en Ron- } \\
\text { cesvalles a través del Camino de la Cruz. }\end{array}$ \\
\hline $\begin{array}{l}\text { 3. Escasa competitividad por la falta de adaptación a } \\
\text { nuevas técnicas de gestión empresarial. }\end{array}$ & 3. Promoción de la Vía Verde del Noroeste de Murcia. \\
\hline 4. Aumento del paro y de la precariedad laboral. & $\begin{array}{l}\text { 4. Promoción de otras vías de acceso a Caravaca desde otras } \\
\text { provincias, incluido el Camino de San Juan de la Cruz. }\end{array}$ \\
\hline $\begin{array}{l}\text { 5. Falta de coordinación entre ayuntamientos y Adminis- } \\
\text { tración autonómica. }\end{array}$ & $\begin{array}{l}\text { 5. Posibilidad de acceder a fondos europeos estructurales por } \\
\text { tratarse de un espacio vaciado. }\end{array}$ \\
\hline $\begin{array}{l}\text { 6. Caída de los establecimientos hoteleros por falta de } \\
\text { ocupación en años no jubilares, que son casi todos menos } \\
\text { cada siete años. }\end{array}$ & $\begin{array}{l}\text { 6. Puesta en valor de todo el patrimonio monumental, cultural } \\
\text { y etnográfico. }\end{array}$ \\
\hline 7. Envejecimiento poblacional y caída de la natalidad. & $\begin{array}{l}\text { 7. Mejora en la formación de empresarios y trabajadores en } \\
\text { actividades terciarias. }\end{array}$ \\
\hline 8. Abandono de la población en las pedanías existentes. & $\begin{array}{l}\text { 8. Aprovechamiento de la autovía que conecta Murcia (A7) con } \\
\text { Caravaca. }\end{array}$ \\
\hline 9. Disminución de los recursos hídricos. & 9. Promoción de la ciudad en ferias y eventos internacionales. \\
\hline 10. Edificios históricos en mal estado que amenazan ruina. & $\begin{array}{l}\text { 10. Implantación de las tecnologías de la información y la } \\
\text { comunicación (TIC) para la promoción de este producto turís- } \\
\text { tico. }\end{array}$ \\
\hline 11. Convertir la ciudad en lugar de paso para unas horas. & $\begin{array}{l}\text { 11. Proximidad de áreas turísticas como Murcia, Lorca o la } \\
\text { costa mediterránea. }\end{array}$ \\
\hline $\begin{array}{l}\text { 12. Promoción de visitas que generan pocos ingresos (ter- } \\
\text { cera edad o escolares) que, a pesar de ser muy loable, } \\
\text { puede dificultar la llegada de turistas con más poder ad- } \\
\text { quisitivo. }\end{array}$ & \\
\hline
\end{tabular}

Fuente: elaboración propia.

\subsection{Datos socioeconómicos relevantes}

El análisis de las entrevistas realizadas y la información proporcionada por las instituciones públicas señalan una notable diferencia en la llegada de visitantes a la ciudad de Caravaca en relación con los años jubilares y con los que son ordinarios (Figura 4). Observando esa evolución en los años jubilares (2003, 2010 y 2017), el número de vistas supone en muchos casos un incremento de más de un 901,78\%, como ha ocurrido en el último año jubilar (2017) en comparación con el año anterior (2016). Es destacable un cierto estancamiento en los años que no son jubilares, lo cual repercute en las expectativas de crecimiento turístico de la ciudad. Otro dato interesante sería el importante crecimiento de visitantes en los años jubilares, con un incremento entre el primer año jubilar (2003) y el último (2017) de un $28,52 \%$. Sin datos concluyentes, las autoridades indicaron que se podría llegar durante ese último año a más de 800.000 visitas a la ciudad, lo que supondría un impacto económico en la comarca de unos 65 millones de euros ${ }^{1}$.

En relación con el gasto turístico, se estima un gasto diferenciado entre aquellos que vienen para un solo día de aquellos que pasan por lo menos una noche. Se ofertan un total de 919 plazas hoteleras en catorce alojamientos (Tabla 9) entre hoteles (4), hospederías (5), apartamentos (4), albergues (1) y alojamientos rurales (37). El gasto estimado para el visitante de un día es de 37,80 € y con alojamiento de una noche supondría $92,8 €$.

La distribución estimada del gasto indicaría un porcentaje del 57,4\% en comida/restauración, un $29,8 \%$ en compra de recuerdos y regalos y, finalmente, un 12,8\% en museos. Cuando existe alojamiento, la distribución del gasto medio ocuparía los mayores porcentajes en el alojamiento $(42,6 \%)$ y en la comida (28,9\%); el resto se distribuye entre la compra de recuerdos $(6,3 \%)$, la entrada a museos $(8,4 \%)$, los gastos complementarios $(6,7 \%)$ y otros gastos no especificados $(7,1 \%)$ (Figura 5$)$.

${ }^{1} \underline{\mathrm{https}: / / \text { cadenaser.com/emisora/2017/02/11/radio murcia/1486813391 710298.html }}$ 


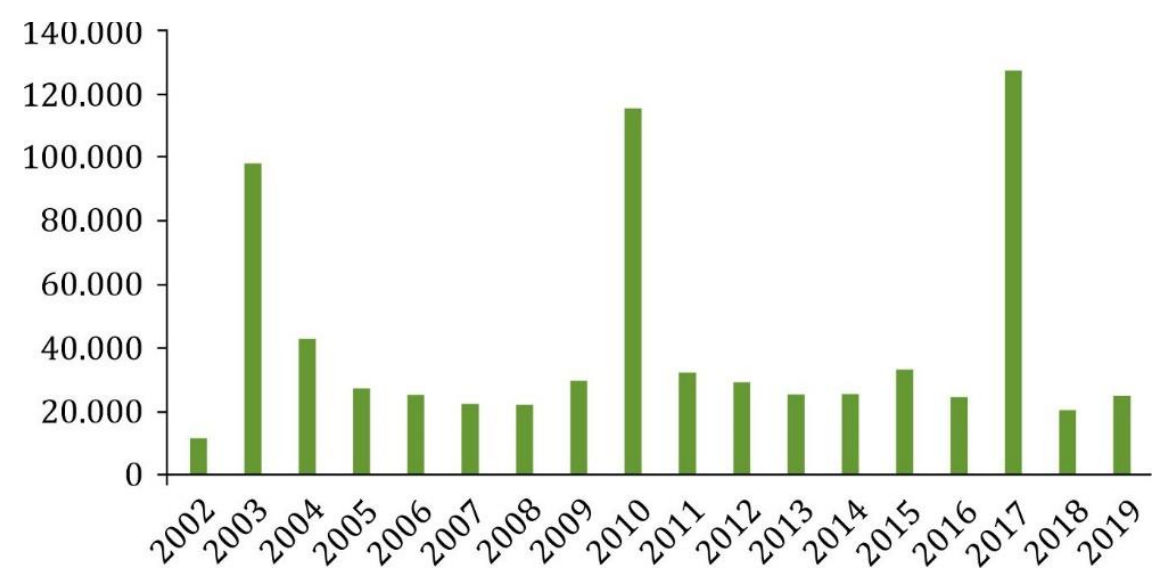

Figura 4. Evolución de las visitas a Caravaca de la Cruz (2002-2019). Fuente: Oficina de Turismo de Caravaca de la Cruz.

Tabla 9. Plazas de alojamiento en el municipio de Caravaca

\begin{tabular}{lcc}
\hline Nombre establecimiento & Número plazas & Categoría \\
\hline Hotel Central (cerrado) & 51 & $* * *$ \\
Hotel El Llano & 100 & $* *$ \\
Hotel El Zorro & 32 & $* *$ \\
Hotel Malena & 32 & $* *$ \\
Hospedería El Carmen & 54 & \\
Hospedería Jardines Casablanca & 16 & \\
Hospedería Almunia & 21 & \\
Hospedería El Molino & 28 & \\
Hospedería Pedro Barreda & 10 & \\
Apartamentos Aixa I & 72 & \\
Apartamentos Aixa II & 96 & \\
Apartamentos Cuesta Cruz & 33 & \\
Apartamentos D. Álvaro & 3 & \\
Albergue Peregrinos & 24 & \\
Alojamientos rurales (37) & 347 & \\
TOTAL & 919 & \\
\hline
\end{tabular}

Fuente: elaboración propia.

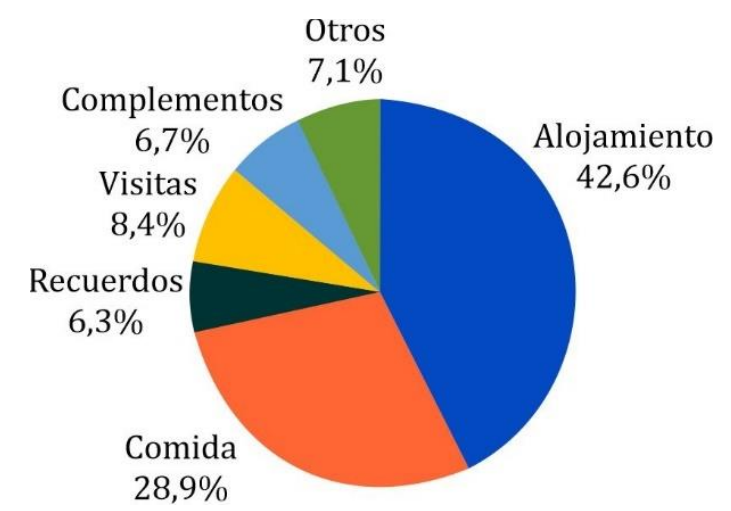

Figura 5. Distribución porcentual del gasto medio.

Fuente: elaboración propia.

\subsection{Detección de los problemas más relevantes}

El análisis de las entrevistas y, básicamente, las respuestas a las preguntas 27 y 28 señalan una serie de problemas o impedimentos que frenan el desarrollo de Caravaca como destino turístico relevan- 
te. En la Figura 6 indicamos los más destacados desde el punto de vista porcentual, que serían el déficit de alojamientos hoteleros y de albergues. La aplicación de un índice tradicional como es el Defert, que representa la relación existente entre capacidad de acogida, expresada generalmente en número de plazas hoteleras, y la población residente, indica un valor de 3,57, dato que señala un tasa de función turística baja respecto a los alojamientos.

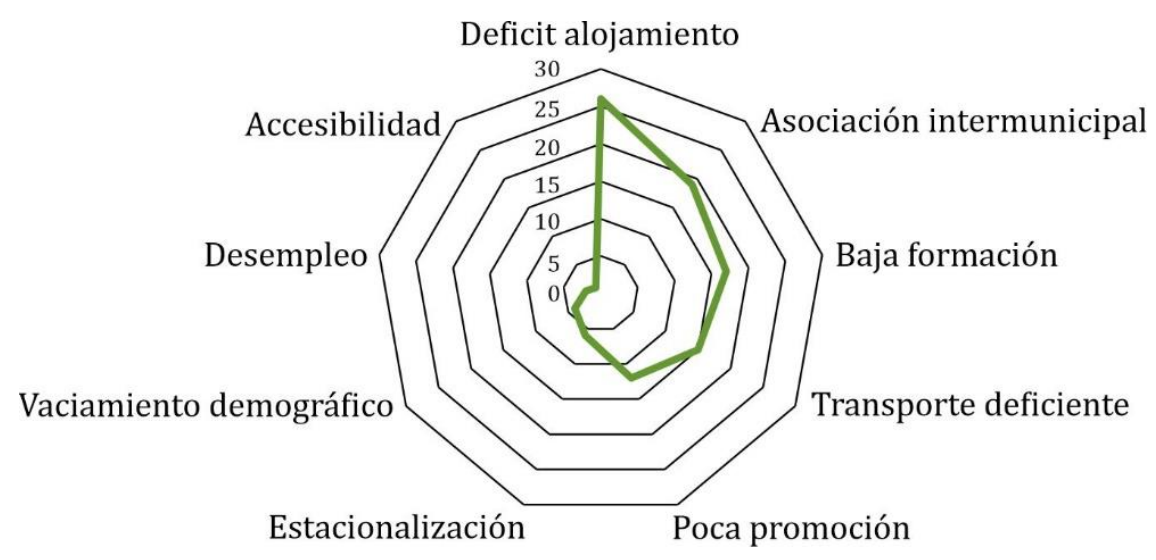

Figura 6. Principales problemas para la consolidación del turismo en Caravaca de la Cruz. Fuente: elaboración propia.

La falta de un mayor asociacionismo para desarrollar planes de conjunto entre las distintas Administraciones Públicas es otra cuestión que debería mejorarse. La baja oferta en la formación de profesionales, un transporte público deficiente que conecte con mayor frecuencia la ciudad con Murcia capital y la falta de promoción de eventos y de marketing turístico de la ciudad son otros factores destacados en esta serie de debilidades que precisan de una intervención y que, si se resuelven, mejorarán la gestión y la promoción turística.

Finalmente, añadimos otras cuestiones que precisan un mayor grado de intervención por tratarse de problemas estructurales que implican acciones a largo y a medio plazo. Destacamos el importante estancamiento demográfico, pues la comarca cuenta con municipios que incluso pierden población, como es el caso de Moratalla (Morales Yago, 2021), de la misma manera que sucede en algunas cabeceras comarcales de Galicia (Martínez y Peón, 2015). Por otro lado, los niveles desempleo tanto de la comarca de Caravaca (un 20,8\%) como de la ciudad de Caravaca (un 17,6\%) son superiores a la Región de Murcia (un 15,4\%). El fortalecimiento de este turismo de rural de interior frenaría la situación demográfica, del mismo modo que ha sucedido en áreas rurales de Cerdeña (Lampreu, 2020), y se alinearía con las nuevas tendencias de un turismo sostenible y "lento" (Pistocchi, Curiazi y Dallaria, 2018).

\subsection{La promoción de los Caminos a Caravaca de la Cruz}

Con motivo de los años jubilares 2003 y 2010, se propuso, a través de la financiación de la desaparecida Caja de Ahorros del Mediterráneo (CAM), la señalización en total de siete caminos o rutas situadas desde distintas ciudades de la Región de Murcia, que proponían generalmente entre dos y siete etapas, recorriendo un mínimo de $27 \mathrm{~km}$ (Camino de Letur) y un máximo de $138 \mathrm{~km}$ (Camino del Apóstol). Se podrían realizar a pie, en bicicleta o a caballo. Pasados los años, esta propuesta ha quedado reducida al denominado Camino de Levante, que uniría la ciudad de Orihuela (Alicante) y Caravaca, empleando un total de cinco etapas y con un recorrido de 118 kilómetros, pasando por poblaciones como Murcia, Alcantarilla, Mula, Bullas y Cehegín².

La Vía Verde ${ }^{3}$, recuperada a partir del antiguo trazado ferroviario que unía Murcia con Caravaca (entre 1933 y 1971), es el eje de este Camino que registra una afluencia a lo largo de todo el año, pero

\footnotetext{
${ }^{2}$ https://www.murciaturistica.es/camino-de-la-cruz/etapas/

${ }^{3}$ http://www.viasverdes.com/itinerarios/itinerario.asp?id=88
} 
que necesita una mayor promoción de infraestructuras, como albergues y espacios de restauración, para consolidarse como destino permanente. El Camino Natural Vía Verde del Noroeste de la Región de Murcia es una ruta acondicionada para usuarios no motorizados. Se trata de un itinerario ecoturístico con sentido de peregrinaje y que aprovecha antiguas estaciones y apeaderos recuperados como albergues para el usuario. Atraviesa viaductos y túneles, con un paisaje lleno de contrastes, tiene una longitud de 78 kilómetros y una potencialidad como recurso turístico destacable dentro de las nuevas modalidades de movilidad originadas por el turismo de interior (Collings-Kreiner, 2014), integrado dentro del sistema turístico global existente (Mojshevich, Raisovna, Aleksandrovich, Kamilevich y Valerevna, 2017) (Figura 7).

En la Figura 8 se recogen los Caminos de la Vera Cruz de Caravaca en la Región de Murcia y en Alicante y Albacete.
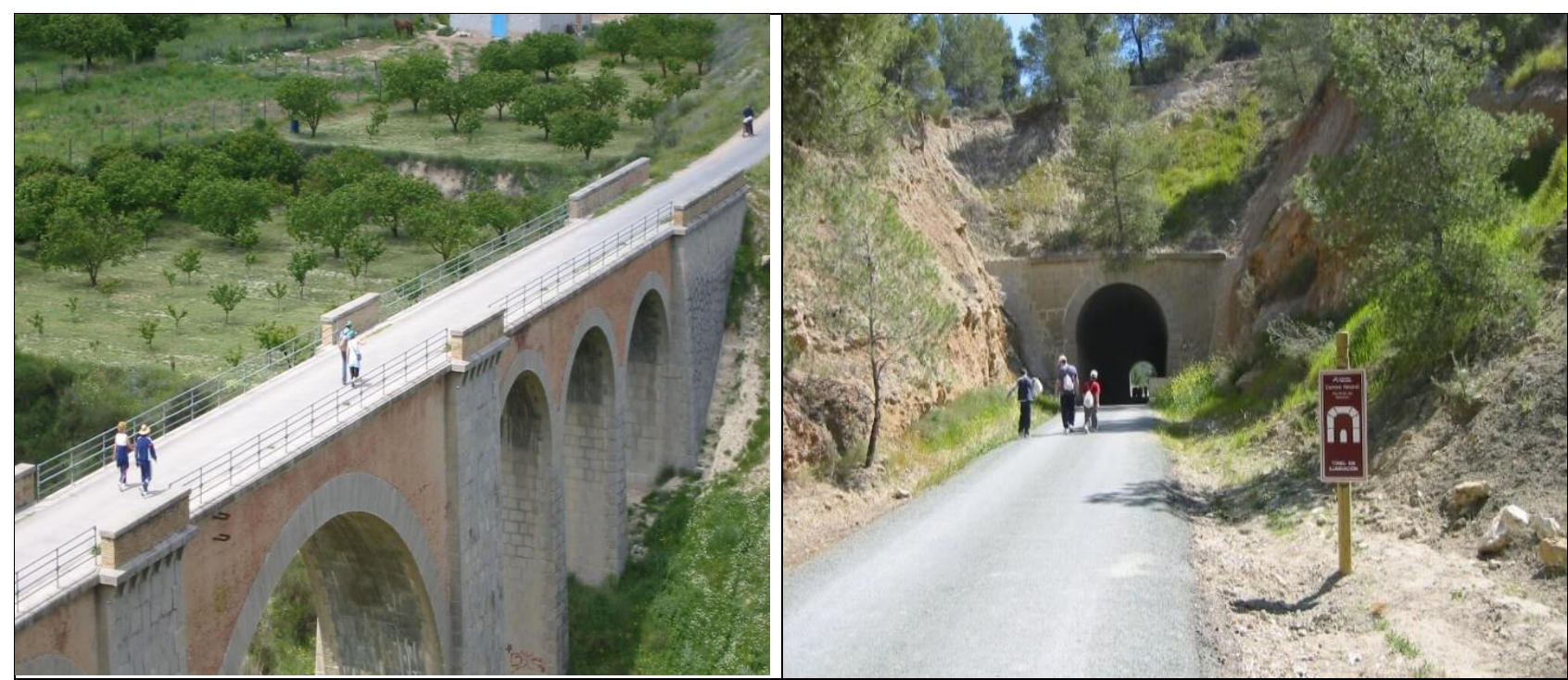

Figura 7. Tramos del Camino Natural Vía Verde del Noroeste de la Región de Murcia sobre el antiguo trazado ferroviario (2019). Fuente: https://www.murciaturistica.es/es/via verde noroeste/

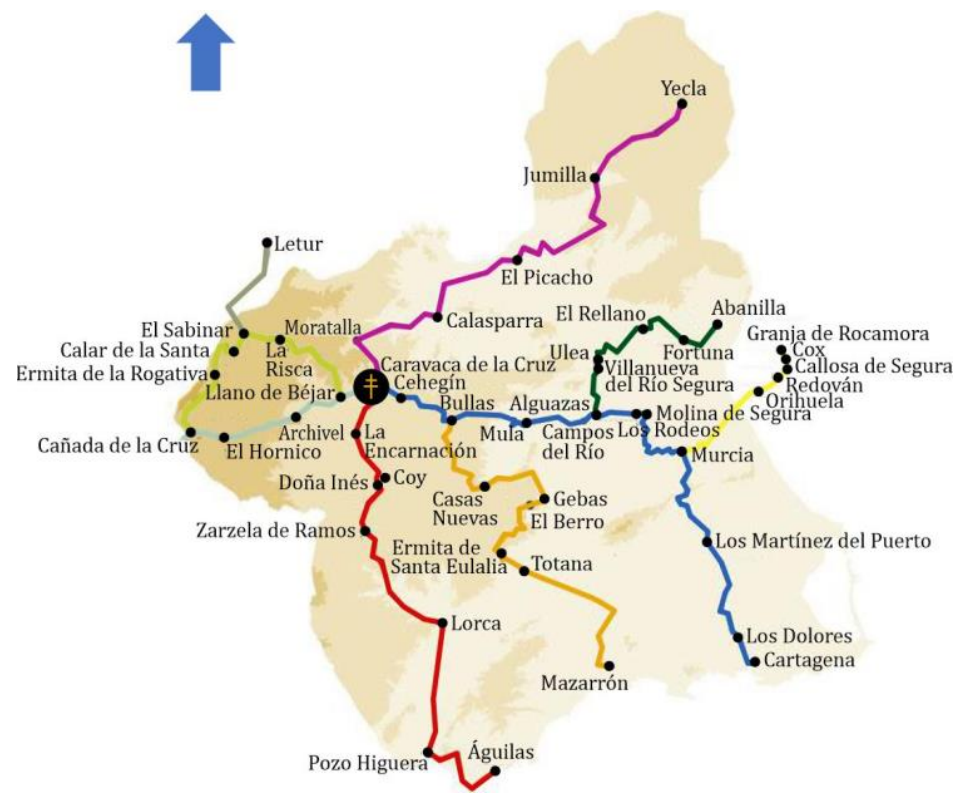

Figura 8. Los Caminos de la Vera Cruz de Caravaca dentro de la Región de Murcia, Alicante y Albacete. Nota: Escala: 1: 1.850.000. Fuente: http://www.lacruzdecaravaca.com/anos-santos/los-caminos-la-veracruz/ (2017). 
Con motivo del año jubilar 2017, se sellaron unas 14.000 credenciales de personas que completaron este itinerario ${ }^{4}$, un dato todavía muy alejado de los grandes caminos de peregrinación como es el caso de Santiago de Compostela ${ }^{5}$ o incluso la visita a los importantes santuarios dispersos por nuestro país como El Rocío ${ }^{6}$ (Huelva), Covadonga ${ }^{7}$ (Asturias), El Pilar ${ }^{8}$ (Zaragoza), Monserrat ${ }^{9}$ (Barcelona) o Guadalupe ${ }^{10}$ (Cáceres).

Destacamos como una iniciativa interesante pero todavía sin consolidar el denominado Camino de la Cruz (Figura 9), que se inicia en Roncesvalles, discurre por el Camino de Santiago, atravesando cinco comunidades autónomas -Navarra, Aragón, Valencia, Castilla-La Mancha y Murcia-, con un recorrido de casi 900 kilómetros, y que por el momento es un gran desconocido para la mayoría de los seguidores de esta modalidad turística. Tiene la peculiaridad de enlazar con el Camino de Santiago a la altura de Puente de la Reina para los peregrinos que proceden de Somport-Jaca, o seguir el mismo trazado para los que inician desde Saint Jean Pied de Pont.

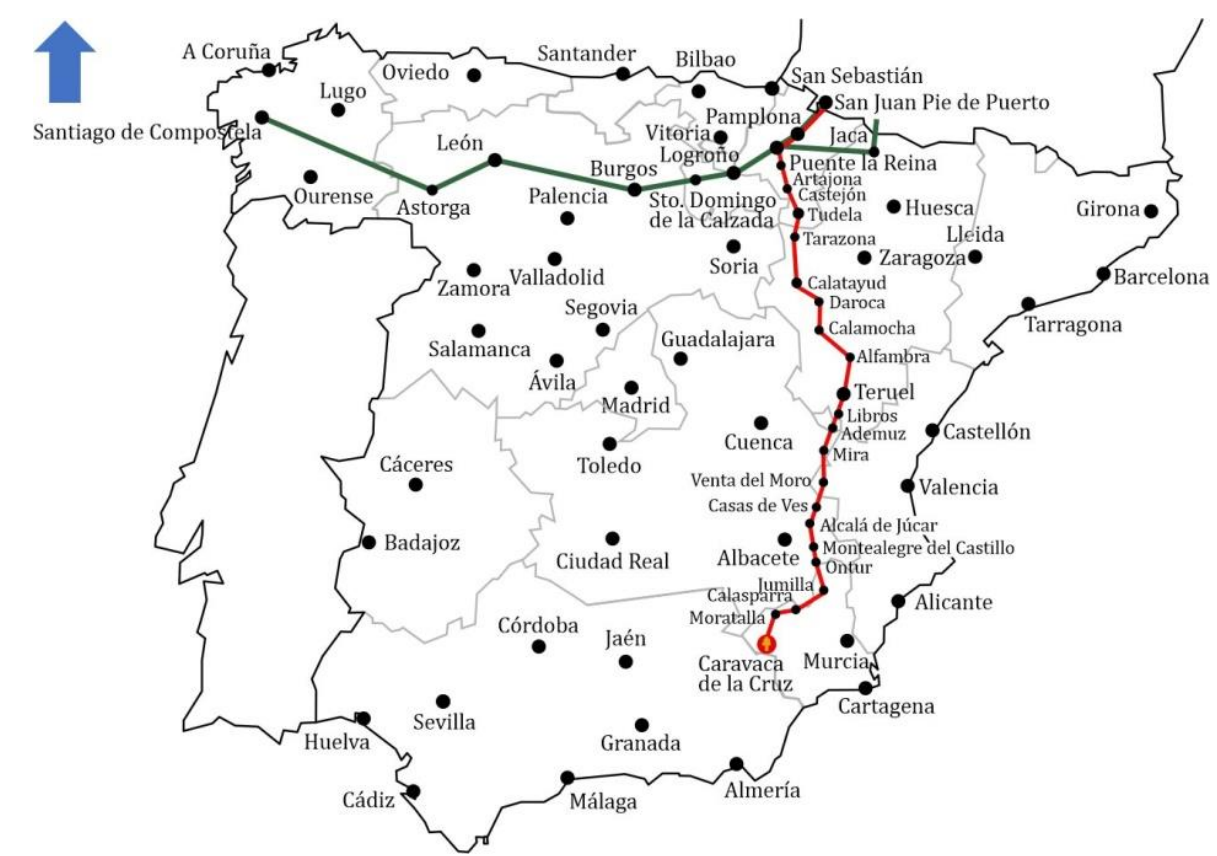

Figura 9. El Camino de la Cruz desde Roncesvalles a Caravaca de la Cruz (2017). Nota: Escala: 1: 7.400.000. Fuente: De la historia de mira - Trabajo propio, CC BY-SA 3.0, https://commons.wikimedia.org/w/index.php?curid=31506181

También se ha intentado promocionar la Ruta de San Juan de la Cruz desde Beas del Segura (Jaén) hasta Caravaca ${ }^{11}$, siguiendo el camino del santo español, pero esta iniciativa ha dado escasos resultados. En las entrevistas realizadas a expertos, estos indicaban como causas de esta baja incidencia la falta de promoción, la necesidad de hacer una señalética adecuada, la difusión masiva a través de redes sociales y la necesidad de una decisiva intervención de las autoridades públicas, que deberían unirse para promover los distintos espacios por donde pasa este Camino. Esta es una cuestión interesante y necesaria para estas localidades de la España interior (Cànoves et al., 2014), que están sufriendo un gran proceso de despoblación como serían, entre otras, las provincias de Teruel, Cuenca o Albacete

\footnotetext{
${ }^{4}$ https://diocesisdecartagena.org/caravaca-cruz-anyo-jubilar-2017/

5 https://www.caminodesantiago.gal/es/inicio

${ }^{6}$ https://www.andalucia.org/es/conoce-andalucia/arte-cultura-y-tradiciones/el-rocio/la-aldea-de-el-rocio

7 https://santuariodecovadonga.com/

${ }^{8}$ https://www.turismodearagon.com/ficha/basilica-de-nuestra-senora-del-pilar-zaragoza/

${ }_{9}$ https://abadiamontserrat.cat/

$10 \mathrm{http://monasterioguadalupe.com/}$

${ }^{11}$ https://caminodesanjuandelacruz.org/\#inicio
} 
(del Romero, 2018), con unas actuaciones que demandarían una nueva estrategia territorial (Comisión Europea, 1999).

\section{Discusión y conclusiones}

Los resultados de este trabajo señalan que Caravaca de la Cruz es un destino turístico y cultural interesante, de grandes potencialidades, pero aún en una fase inicial de consolidación. Tiene la garantía de tratarse de un itinerario que por lo menos cada siete años alberga un jubileo conocido y apreciado dentro de la cultura cristiana y que también se abre paso por otras motivaciones como serían el aspecto cultural, ambiental, paisajístico o deportivo. A diferencia de otros "Caminos", como podría ser el Camino de Santiago (Martínez, Castro y Fraiz, 2018; Santos, 1999), en general plantea recorridos cortos, menos de 100 kilómetros, salvo el desconocido Camino de la Cruz, que comienza en Roncesvalles a 900 kilómetros de Caravaca. Trabajos anteriores realizados por Andrés y Espejo (2006), García (2010) o Morales (2018), expusieron las potencialidades de este espacio, señalando datos que indicaban un ritmo de crecimiento de visitantes importante. En los último cinco años se observa un ritmo de crecimiento lento, incluso en algunos años en retroceso, sin contar, por supuesto, la situación acaecida en 2020 y 2021 por la crisis sanitaria generada por la COVID-19 que ha paralizado el volumen turístico en casi un $100 \%$.

No obstante, los importantes esfuerzos realizados por la Administración Pública en cuanto a inversiones en infraestructuras y a la apertura de nuevos espacios culturales, así como las inversiones privadas en la dotación de nuevos espacios de restauración y alojamiento, no se están traduciendo en hacer de Caravaca un destino cultural y religioso de primer orden; de hecho, las visitas son muy cortas respecto al tiempo de permanencia en la ciudad, la mayoría son estancias de un día, con una duración media nunca superior a ocho horas, lo que no favorece la asistencia a los distintos recursos turísticos existentes que, aparte del jubileo, se ofrecen como la Fiesta de los Caballos del Vino, declarada en 2020 Patrimonio Cultural Inmaterial de la Humanidad por la UNESCO, o la Fiesta de Las Cuadrillas, desarrollada en la pedanía de Barranda y calificada de interés turístico nacional.

De igual modo que otras ciudades merecedoras de bula papal, como el Camino de Santo Toribio de Liébana, cada siete años y desde 1512, Urda (Toledo), en honor a la Sagrada Imagen del Santísimo Cristo de la Vera-Cruz desde 1994, y Valencia desde 2014 en honor al Santo Cáliz de la Última Cena, estos destinos no terminan de constituirse en itinerarios culturales-religiosos consolidados y con un impacto importante en los trazados que ocupan, tal y como sí sucede con el Camino de Santiago desde hace varias décadas

De los análisis realizados y expuestos en los anteriores apartados de estudio, destacamos la urgente necesidad de llevar a cabo un plan director que aglutine y complemente la iniciativa pública y privada, capaz de ofrecer herramientas de dinamización económica que podrían incrementarse con la consolidación de este destino turístico que presenta un espacio local que, desde hace décadas, intenta conformar uno de los polos de atracción de turismo religioso, rural o de interior de referencia en el SE peninsular y, hasta el momento, no ha logrado conseguirlo.

A continuación, se exponen en estas conclusiones las líneas de trabajo más relevantes:

1. Los planes de promoción turística diseñados deben ajustarse a un plan director general cuyo modelo de gestión debería aglutinar al menos las siguientes líneas de actuación fundamentales:

- Una recuperación integral del patrimonio histórico y artístico de la ciudad y de la comarca. El esfuerzo desarrollado ha sido importante y debe continuar de una forma organizada y sostenible a través de planes bianuales o quinquenales en el futuro. De esta forma se asegurará la recuperación y el mantenimiento de un espacio de alto valor monumental (Molina, 2002).

- Mejorar las infraestructuras de comunicación y acceso a la comarca de Caravaca por el norte, aumentando la conectividad entre La Venta del Olivo (acceso a la A-30), que enlaza con la autovía a Madrid, y a través de Jumilla con la A-33, que enlaza Jumilla con Valencia. Las potenciales llegadas de turistas de la costa tendrían dos focos importantes: el primero la Manga del Mar Menor/Cartagena y el segundo Mazarrón-Águilas, lo que significa una mejora de la conectividad en- 
tre Lorca y Caravaca. La recuperación de la línea ferroviaria entre Murcia-Caravaca, cerrada en 1971, debería someterse a estudio para una mejora de la vertebración territorial.

- La puesta en marcha del aeropuerto internacional de Murcia en Corvera y del aeropuerto internacional de El Altet en Elche-Alicante quedan a una distancia de 87,9 km del primero y de 138,5 $\mathrm{km}$ del segundo, por lo que se debería aprovechar para promover desde estos aeropuertos la visita a Caravaca.

2. Los años jubilares desarrollados cada siete años tienen una importante afluencia, aunque se estima que un porcentaje superior al 50\% son habitantes de la Región de Murcia y provincias limítrofes, lo que indica una baja proyección del jubileo a nivel nacional y aún menos internacional. En los años que no son jubilares, el número de visitantes a la ciudad es muy bajo, lo que impide la creación de más establecimientos hoteleros y de restauración, así como una baja asistencia a museos y actos culturales.

3. La Declaración de Patrimonio Inmaterial de la Humanidad de los Caballos del Vino (Melgares, 1992) y de Fiesta de Interés Turístico Nacional del Festival de Cuadrillas de Barranda debe ser motivo de promoción y difusión de la ciudad como destino cultural de gran importancia.

4. Falta desarrollar mucho más las rutas trazadas de peregrinación a Caravaca. Destacamos el Camino de Levante, que une las ciudades de Orihuela con Caravaca; también es necesario poner en valor la ruta del Apóstol, que une Cartagena con Murcia y por tanto con el Camino de Levante. La ruta de la Cruz, que parte por Roncesvalles y pasa por las provincias de interior de Pamplona, La Rioja, Zaragoza, Teruel, Cuenca y Albacete hasta llegar a Caravaca, debe ser promovida por las distintas comunidades autónomas. Se necesita un gran trabajo de colaboración y la financiación adecuada para que esta propuesta prospere. Actualmente es una ruta en proyecto que debería ponerse en funcionamiento.

5. Es necesaria la promoción y marketing de Caravaca y su comarca como un producto turístico y un itinerario cultural de gran potencialidad a través de operadores de turismo y campañas publicitarias. Es imprescindible la asistencia y presencia institucional en ferias como la Feria Internacional del Turismo (FITUR) y otras de carácter internacional fuera de España; también los contactos estables con mayoristas (operadores de turismo) y la presencia permanente en las redes sociales. Solo así se hará posible la difusión mediática necesaria del proyecto turístico de Caravaca y se garantizará la llegada de visitantes y turistas con más regularidad que el carácter puntual de los años jubilares.

6. El aumento en la formación de las personas en las actividades relacionadas con el turismo es imprescindible. Se requiere el incremento de la formación profesional de los trabajadores relacionados con los servicios de restauración, hostelería, guías turísticos con dominio de varios idiomas, etcétera, teniendo en cuenta que la calidad del capital humano es primordial en el turismo, que es una actividad basada en el cuidado y en la atención que unas personas prestan a otras. En este sentido, habría que vencer el obstáculo que supone la ausencia en Caravaca de algún centro dedicado a la formación y cualificación de profesionales del turismo a partir de los estudios reglados en módulos de grado medio o superior sobre hostelería o restauración.

7. Aplicar obligatoriamente criterios de sostenibilidad (Cebrián, 2001) de acuerdo con la Carta del Turismo Sostenible de Vitoria de 2015 y las recomendaciones de la Organización Mundial del Turismo (OMT) a propósito de la declaración de 2017 como Año del Turismo Sostenible. Solo así se garantizará el equilibrio entre la preservación ambiental, la viabilidad económica y la equidad social en el reparto de beneficios del desarrollo. En un espacio que potencialmente puede iniciarse en la actividad turística es básico tener presente un modelo que asegure la sostenibilidad de la oferta turística y debe ser la garantía en el mantenimiento del turismo ofertado. Por tanto, la adecuada gestión de los recursos hídricos y de los vertidos, la eficiencia energética y el diagnóstico medioambiental deben asegurar un producto basado en el encuentro con la naturaleza y las múltiples posibilidades que ello ofrece: práctica de deportes como senderismo, alpinismo o cicloturismo, visita a espacios arbóreos, a masas de agua o el conocimiento in situ de las tareas agrícolas y ganaderas son oportunidades posibles y originales para el visitante.

8. Se exige una mejora en la calidad y competitividad de los recursos hoteleros y de los espacios gastronómicos. Se requiere una importante cooperación entre la iniciativa pública y privada en as- 
pectos básicos como la creación de paquetes turísticos o la promoción de actividades a lo largo de todo el año de modo que se consiga una mayor ocupación hotelera, que actualmente es baja $(51,6 \%)$. Es preciso mejorar las carencias dotacionales existentes actualmente en cuanto al alojamiento y aumentar su calidad para atraer un turismo que cada vez es más exigente en su demanda de servicios (Pérez, 2004).

9. La participación de las asociaciones de la ciudad, de colectivos y de instituciones privadas es primordial para el desarrollo turístico de la ciudad; las actividades del voluntariado son imprescindibles. Es necesario aumentar los sentimientos de identificación de los ciudadanos con el lugar en el que viven, facilitando el conocimiento de su pasado y sirviendo de atractivo para visitantes y turistas (Zárate, 2010), y como legado para las futuras generaciones (Zárate, 2016).

10. La Región de Murcia ha diseñado en las últimas décadas una serie de planes estratégicos (2006-2012 y 2015-2019), donde se promueve de manera global integrar toda la superficie regional a través de distintas modalidades turísticas. Para el caso de Caravaca y su comarca, se indica el turismo religioso, cultural y de ocio-naturaleza como los principales atractivos. Además, se considera Caravaca como uno de los principales ejes vertebradores del turismo regional, a lo que también deberíamos añadir el turismo gastronómico, la ruta del vino de Bullas y la actividad de senderismo. La realización de estudios científicos es otra cuestión que debería potenciarse a través de las universidades y de otros centros de investigación con la finalidad de analizar y proponer líneas de mejora.

11. La fidelización de las personas que vienen a Caravaca y vuelven a repetir es muy baja. Los datos señalan un porcentaje menor al $15 \%$, es decir, de aquellos que vienen a Caravaca solamente una pequeña parte vuelve a repetir en los cinco años siguientes. Ello implica la necesidad de crear en el visitante la idea de que deberá volver en un tiempo no demasiado lejano para seguir conociendo la ciudad y todo lo que ofrece su entorno. La mayor parte de los peregrinos no se identifican como turistas; solo un $11 \%$ considera la visita a Caravaca como un viaje turístico, aunque la mayor parte de ellos (un 86\%) cataloga la ciudad y su entorno como un lugar que tiene amplias posibilidades turísticas. El perfil de los visitantes se identifica especialmente con el de peregrinos-creyentes: 74,4\%, y en menor medida como turistas: $12,1 \%$, deportistas-caminantes: $9,8 \%$, y viajeros: 3,7\% (Figura 10).

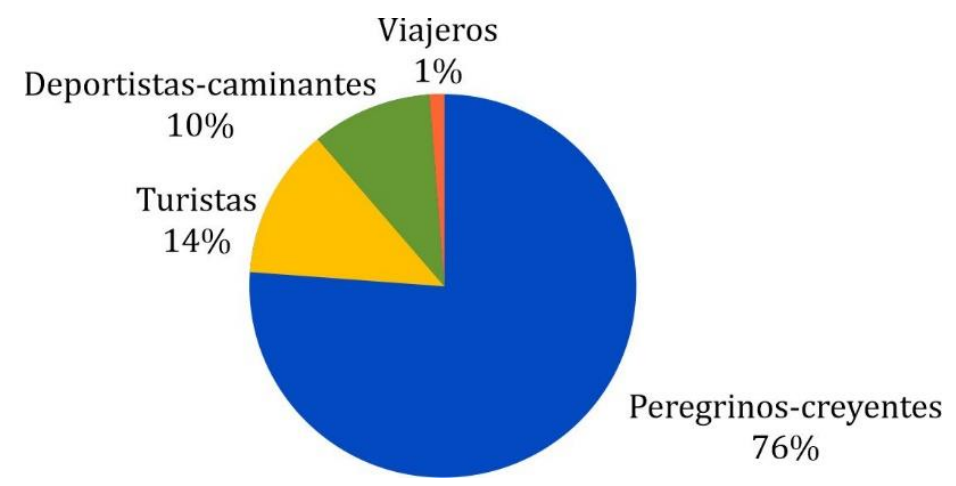

Figura 10. Perfil de los peregrinos que llegan a Caravaca de la Cruz. Fuente: elaboración propia.

12. El turismo de interior basado en las peregrinaciones, cultura, patrimonio, naturaleza y actividades deportivas, tal y como se ha indicado, significa una oportunidad magnífica para completar y diversificar la actividad económica de la ciudad de Caravaca, basada en la agricultura, en la industria del calzado, en la extracción de mármol y en los servicios. Se requiere la promoción de nuevas iniciativas que sean capaces de atraer al potencial turista que, por el momento, identifica Caravaca con una ciudad histórica con un singular jubileo, celebrado cada siete años.

El municipio de Caravaca reúne suficientes potenciales para convertirse en un espacio turístico competitivo de interior, atractivo por su singularidad y especificidad, teniendo en consideración la 
gestión con inteligencia de las fortalezas y de las oportunidades para la puesta en marcha de la actividad turística analizadas a través de este artículo. Nos encontramos en un momento de grandes retos en una economía globalizada y de escalas, de cambio de tendencias y nuevas oportunidades de negocio, con una sociedad que ve aumentar su disponibilidad de tiempo libre y la capacidad de movilidad, lo que obliga a realizar un esfuerzo de creatividad, de visión de futuro, creando condiciones desde la iniciativa pública y privada para diversificar la economía y fortalecer el desarrollo local del noroeste de la provincia de Murcia (Espejo, 1997). El impacto generado por la COVID-19 ha supuesto un espectacular descenso de la actividad turística y económica en general, pero es previsible que cuando se normalice la situación se vuelva a intensificar el turismo. El próximo jubileo de 2024 se propone como un gran escaparate para la ciudad, aunque los años restantes que faltan deberían aprovecharse al máximo para seguir generando expectativas, lanzar nuevas ideas y promocionar la singularidad de Caravaca de la Cruz y su entorno geográfico que irradia a toda la Comunidad Autónoma de Murcia y, por supuesto, debería competir para alcanzar cuotas más altas a nivel nacional e internacional.

\section{Bibliografía}

Andrés Sarasa, J. L. (2002). El turismo cultural como alternativa de áreas deprimidas: el caso del noroeste murciano. En J. S. García Marchante y M. C. Poyato Holgado (Coords.), La función social del patrimonio histórico, el turismo cultural (pp. 65-82). Cuenca: Universidad de Castilla-La Mancha.

Recuperado de: https://dialnet.unirioja.es/servlet/libro?codigo=426590

Andrés Sarasa, J. L., y Espejo Marín, C. (2006). Interacción mito religioso/producto turístico en la imagen de la ciudad: Caravaca de la Cruz (Murcia). Cuadernos de Turismo, 18, 7-62.

Recuperado de: https://revistas.um.es/turismo/article/view/17911

Cànoves Valiente, G., Villarino Pérez, M., Blanco-Romero, E., de Uña Álvarez, E., y Espejo Marín, C. (Eds.). (2014). Turismo de interior: renovarse o morir. Estrategias y productos en Catalunya, Galicia y Murcia. Valencia: Universitat de València, Servei de Publicacions.

Cebrián Abellán, A. (2001). Los proyectos de turismo cultural sostenible en Lorca y Caravaca de la Cruz (Murcia). En A. Cebrián Abellán (Coord.), Turismo cultural y desarrollo sostenible: análisis de áreas patrimoniales (pp. 315-334). Murcia: Universidad de Murcia, Servicio de Publicaciones.

Recuperado de: https://dialnet.unirioja.es/servlet/libro?codigo $=8342$

Cebrián Abellán, A. (2004). Acción local, turismo y patrimonio en la Comunidad de Murcia. Cuadernos de Turismo, 16, 65-85. Recuperado de: https://revistas.um.es/turismo/article/view/18391

Centro Regional de Estadística de Murcia. (2019). Anuario Estadístico de la Región de Murcia 2019. Murcia: Centro Regional de Estadística de Murcia.

Recuperado de: https://econet.carm.es/web/crem/inicio/-/crem/anuario/actual/anuario.html

Chaves, V., y Faber, A. (2019). 0 turismo religioso na sociedade líquido-moderna. Apropriacão da fé pelo trade turístico. Estudos de Religião, 33(2), 291-315.

Recuperado de: https://dialnet.unirioja.es/servlet/articulo?codigo=7433464

Collings-Kreiner, N. (2014). Pilgrimage and mobilities: The 'pilgrimage turn' within the 'new mobilities paradigm. En R.C. Lois-González, X. M. Santos Solla y P. Taboada-De-Zúñiga (Eds.), New tourism in the 21st century: Culture, the city, nature and spirituality (pp. 33-54). Newcastle upon Tyne, UK: Cambridge Scholars Publishing.

Comisión Europea. (1999). ETE-Estrategia Territorial Europea. Hacia un desarrollo equilibrado y sostenible del territorio de la UE. Bruselas, Bélgica: Comisión Europea. Recuperado de: https://ec.europa.eu/regional_policy/sources/docoffic/official/reports/pdf/sum es.pdf

Consejería de Obras Públicas y Ordenación del Territorio. (2008). Plan general de ordenación urbana de Caravaca de la Cruz. Caravaca de la Cruz: Ayuntamiento de Caravaca de la Cruz, Consejería de Obras Públicas y Ordenación del Territorio. Recuperado de: https://www.caravaca.org/index.php/ayuntamiento/normativamunicipal/plan-general-kmz

del Romero, L. (2018). Despoblación y abandono de la España rural. El imposible vencido. Valencia: Tirant lo Blanch.

Espejo Marín, C. (1997). La oferta de turismo rural en el Noroeste de la Región de Murcia. Geographicalia, 35, 87-97. DOI: https://doi.org/10.26754/ojs geoph/geoph.1997351693

Espejo Marín, C. (2008). El papel de los instrumentos de planificación en las dinámicas productivas y territoriales. En F. Cebrián Abellán (Coord.), Turismo y desarrollo local (pp. 161-170). Cuenca: Universidad de Castilla-La Mancha, Servicio de Publicaciones.

Recuperado de: https://books.google.es/books?hl=en\&lr=\&id= NjEMwc1i AC\&oi=fnd\&pg=RA1PA161\&dq=info:UDURv kQG9II:scholar.google.com\&ots=LQFdj838oj\&sig=K-fMeuueafc68H4InKjZDKoubs\&redir esc $=\mathrm{y} \# \mathrm{v}=$ onepage $\& q \& \mathrm{f}=$ false 
García Ayala, J. A. (2010). Próximo destino: Caravaca de la Cruz. Gran Tour: Revista de Investigaciones Turísticas, 1, 79-96. Recuperado de:

https://www.researchgate.net/publication/277268291 Proximo destino Caravaca de la Cruz

García Marín, R. (Ed.). (2016). Lorca: ciudad histórica del Mediterráneo. Murcia: Fundación Séneca. Recuperado de: http://hdl.handle.net/10045/61603

García Pérez, N. (2003). Huellas. Repercusiones del turismo cultural en la Región de Murcia. Cuadernos de Turismo, 12, 119-130. Recuperado de: http://revistas.um.es/turismo/article/view/19151

Lampreu, S. (2020). Estrategias de desarrollo territorial y turismo contra la despoblación de las áreas rurales en Cerdeña (Italia). Revista Galega de Economía, 29(2), 1-20. DOI: https://doi.org/10.15304/rge.29.2.6908

Ley 3/1992, de 30 de julio, de patrimonio de la Comunidad Autónoma de la Región de Murcia. Lexislación consolidada. Comunidad Autónoma de la Región de Murcia. Boletín Oficial de la Región de Murcia, 189, de 14 de agosto de 1992 y Boletín Oficial del Estado, 22, de 26 de enero de 1993. Referencia: BOE-A-1993-1775. Recuperado de: https://www.boe.es/buscar/act.php?id=BOE-A-1993-1775

Martínez Roget, F., Castro Domínguez, M. N., y Fraiz Brea, J. A. (2018). 0 turismo como fonte de riqueza en Galicia: análise dalgunhas experiencias. Revista Galega de Economía, 27(3), 65-80.

DOI: https://doi.org/10.15304/rge.27.3.5437

Martínez, X., y Peón, D. (2015). Patróns de despoboamento do rural galego: unha análise por comarcas. Revista Galega de Economía, 24(1), 63-78 DOI: https://doi.org/10.15304/rge.24.1.2698

Melgares Guerrero, J. A. (1992). Caballos del vino. En VV.AA., Gran Enciclopedia de la Región de Murcia, t. 2 (p. 249). Murcia: Ayalga.

Millán Escriche, M. (2004). Ocio y turismo en la Región de Murcia. Estrategias para su diversificación. Cuadernos de Turismo, 14, 113-137. Recuperado de: https://revistas.um.es/turismo/article/view/18571

Mojshevich, B., Raisovna, L., Aleksandrovich, O., Kamilevich, N., y Valerevna, E. (2017). Religious tourism in the tourism system. Revista San Gregorio, 20, 96-103.

Recuperado de: http://revista.sangregorio.edu.ec/index.php/REVISTASANGREGORIO/article/view/520

Molina Molina, A. L. (2002). Evolución urbana de Caravaca (s. XIII-1850). En J. J. Eiroa García, A. L. Molina Molina, J. A. Eiroa Rodríguez, J. L. Andrés Sarasa y C. Espejo Marín, Evolución urbana y actividades económicas en los núcleos históricos (pp. 49-69). Murcia: Universidad de Murcia, Grupo de investigación y Geografía del Urbanismo. Recuperado de: https://www.um.es/grupos/grupo-his-geog-urbanismo/est-historicos-5.pdf

Morales Yago, F. J. (2018). Caravaca de la Cruz (Murcia): paisaje y patrimonio al servicio del turismo cultural y religioso. Boletín de la Real Sociedad Geográfica, 153, 201-234.

Recuperado de: https://dialnet.unirioja.es/servlet/articulo?codigo=7002583

Morales Yago, F. J. (2021). Desarrollo local y vaciamiento demográfico en Moratalla (Murcia, España) ¿un proceso reversible a través de la promoción turística? Terra, 8. DOI: https://doi.org/10.7203/terra.8.18435

Pérez de las Heras, M. (2004). Manual del turismo sostenible: cómo conseguir un turismo social, económico y ambientalmente responsable. Madrid: Mundi-Prensa.

Pistocchi, F., Curiazi, R., y Dallaria, F. (2018). Nuevos peregrinos y nuevos turistas para la sostenibilidad medioambiental: el turismo lento como vía para la conservación de la autenticidad del patrimonio tangible e intangible de un territorio. Antropología. Cuadernos de Investigación, 19, 53-72.

DOI: https://doi.org/10.26807/ant.v0i19.138

Sánchez Romero, G. (2009). Ensayo histórico sobre los caminos de la Vera Cruz de Caravaca. Murgetana, 121, 31-64. Recuperado de: https://dialnet.unirioja.es/servlet/articulo?codigo $=3107433$

Santos Solla, X. M. (1999). Mitos y realidades del Xacobeo. Boletín de la Asociación de Geógrafos Españoles, 28, 103-118. Recuperado de: https://dialnet.unirioja.es/servlet/articulo?codigo=1318654

Steil, C. A., y Marques, B. (2008). El Camino de las Misiones: reflexiones teórico-metodológicas a partir de una experiencia de peregrinación contemporánea. Ciencias Sociales y Religión/Ciências Sociais e Religião, 10(10), 17-48. DOI: https://doi.org/10.22456/1982-2650.6708

Torres Fontes, J. (1969). Colección de documentos para la Historia del Reino de Murcia. II: Documentos del s. XIII. Murcia: Real Academia Alfonso X El Sabio.

Velasco González, M. (2009). Gestión turística del patrimonio cultural: enfoques para un desarrollo sostenible del turismo cultural. Cuadernos de Turismo, 23, 237-235.

Recuperado de: https://revistas.um.es/turismo/article/view/70121

Vera Rebollo, J. F., López Palomeque, F., Marchena Gómez, M., y Antón Clavé, S. (Coords.). (2011). Análisis territorial del turismo y planificación de destinos turísticos. Valencia: Tirant lo Blanch.

Recuperado de: https://dialnet.unirioja.es/servlet/libro?codigo $=675851$

Zárate Martín, M. A. (2009). Paisajes culturales urbanos españoles: la necesaria conciliación entre ordenación del territorio y urbanismo. Boletín de la Real Sociedad Geográfica, 145, 247-270.

Recuperado de: https://dialnet.unirioja.es/servlet/articulo?codigo $=3146300$ 
Zárate Martín, M. A. (2010). Paisajes culturales urbanos, un legado para conservar. Anales de Geografía de la Universidad Complutense, 30(2), 187-210.

Recuperado de: https://revistas.ucm.es/index.php/AGUC/article/view/31868

Zárate Martín, M. A. (2016). Paisajes culturales urbanos, oportunidad para la conservación del patrimonio y el turismo sostenible. Estudios Geográficos, 77(281), 693-728.

Recuperado de: http://estudiosgeograficos.revistas.csic.es/index.php/estudiosgeograficos/article/view/501

\section{Sitiografía}

http://caminodesanjuandelacruz.org/\#recorrido

http://turismodemurcia.es/es

http://www.caravaca.org/

http://www.fiestadelascuadrillas.com/https://www.eixoatlantico.com/images/SIE/181129-sie-turismo barce-

los/informe estudio camino santiago-esp laura-dopeso.pdf

http://www.regmurcia.com/servlet/s.Sl?sit=c,371,m,1071\&r=CeAP-1521-C 49 DETALLE CENTRO

http://www.turismocaravaca.com/es/

https://es.wikipedia.org/wiki/Camino de la Vera Cruz desde los Pirineos

https://hoteles.muchoviaje.com/espana/murcia/hoteles-en-caravaca-de-la-cruz/escdc.html

https://www.murciaturistica.es/camino-de-la-cruz/etapas/

https://www.murciaturistica.es/es/destinos y localidades/

https://www.murciaturistica.es/es/noroeste/

https://www.regmurcia.com/servlet/s.Sl?sit=a,74,c,369,m,1218\&r=ReP-21348 